\title{
Diagnóstico para el uso de la realidad aumentada como recurso didáctico en UNAH-TEC Danlí
}

José Francisco Pérez

Sarahí Del Carmen Lagos

Centro Regional Tecnológico UNAH-TEC Danlí

\section{Resumen}

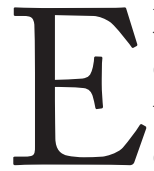

1 objetivo de la investigación consistió en realizar un diagnóstico para el uso de la realidad aumentada (RA), como recurso didáctico en el proceso enseñanza aprendizaje para los estudiantes de la Universidad Nacional Autónoma de Honduras, Centro Regional Tecnológico de Danlí, UNAH-TEC Danlí. En el proceso de investigación se utilizaron técnicas para la recolección de información como la encuesta y la entrevista aplicadas a docentes y estudiantes. Los resultados reflejan que existe un alto interés y aceptación por parte de los estudiantes y docentes de UNAH-TEC Danlí con respecto al uso de la RA como parte de los materiales y contenidos de estudio en sus asignaturas, además de las condiciones institucionales para implementar esta tecnología en el proceso formativo de los estudiantes que se forman en sus aulas universitarias.

Palabras clave: realidad virtual, realidad aumentada, TIC, códigos $\mathrm{QR}$, dispositivos vestibles.

\section{Abstract}

The objective of the research was to conduct an assessment of the use of augmented reality (AR), as a teaching resource in the tea- ching-learning process for students at the National Autonomous University of Honduras, Regional Technology Center Danlí (UNAHTEC Danlí). In the process of research we used techniques and tools for gathering key information, such as surveys and interviews with teachers and students. Once the

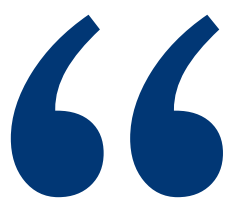
...que existe un alto interés por parte de los estudiantes $y$ docentes de UNAH-TEC

\section{Danli con respecto al uso} de la $R A$ como parte de los materiales y contenidos de estudio que utilizarán en sus asignaturas...

analysis was done became clearly established that there is a high interest from students UNAH-TEC Danlí regarding the use of $A R$ as part of the material and content of study that utilized in their subjects and who is the potential to implement this technology in practice, establishing a positive conclusion about the acceptance of this tech- nology in the teaching-learning process in this study center.

Keywords: teaching and learning, diagnosis, augmented reality, ICT.

\section{Introducción}

La realidad aumentada (RA) se ha desarrollado discretamente en los últimos años, sin embargo la explosión de la industria de las Tecnologías de la Información y Comunicación, (TIC), y particularmente la industria de los dispositivos móviles, han permitido el desarrollo de esta tecnología que actualmente marca una tendencia en la forma de incorporar contenidos al mundo real a partir de nuevas tecnologías y contenidos virtuales. Sus usos van desde el área de publicidad, el mercadeo como también áreas de la salud, transporte, redes sociales y la educación.

El presente artículo centra su atención en una aproximación preliminar para identificar las condiciones que a nivel docente, estudiantil e institucional existen en el Centro UNAH-TEC Danlí para utilizar la RA como material didáctico en el proceso formativo de los estudiantes de la carrera de Informática Administrativa, con el propósito de 
que éste sea pertinente a los desarrollos tecnológicos e innovadores de la educación universitaria actual, además reducir costos en la adquisición de recursos de apoyo educativo y aprovechar el equipo tecnológico con que cuenta el Centro Regional. El término y la tecnología de realidad aumentada es relativamente nuevo, sin embargo las grandes empresas e instituciones se han dado cuenta del potencial de la misma y han comenzado a adoptarla en los productos y servicios que ofrecen.

Según Parreño (2010) "La realidad aumentada, aplicada al marketing, abre numerosas oportunidades para propiciar la decisión de compra del consumidor. Éste puede ver cómo un producto cobra vida mediante una pantalla en la que se superponen imágenes e información digital a la del entorno real que está viendo en ese mismo momento". Este autor cita el caso de España, donde

los consumidores ya han podido ver cómo empresas como El Corte Inglés o Doritos emplean esta novedosa tecnología para promocionar sus productos.

Debido a que esta tecnología es hoy de fácil acceso para la mayoría de las personas, surge la iniciativa de mostrar a la comunidad académica de UNAH TEC-Danlí, el potencial educativo que ofrece la realidad aumentada, e identificar las con-

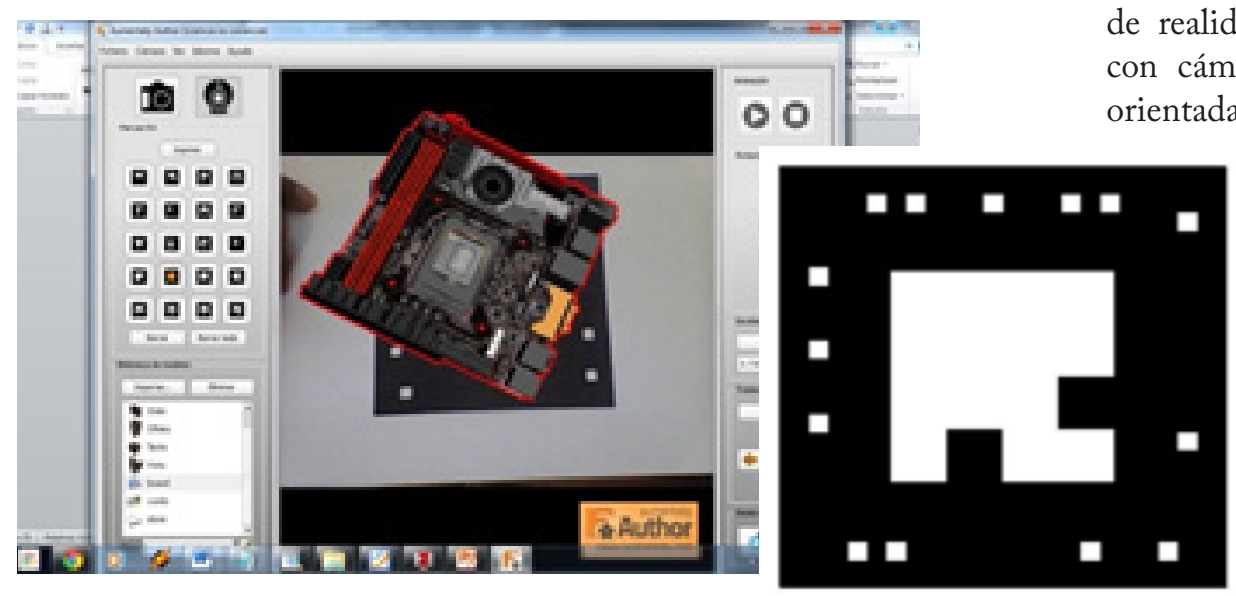

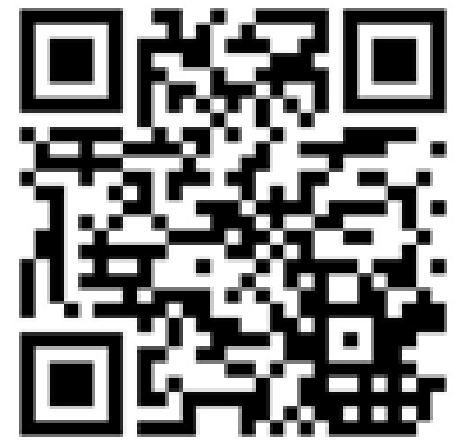

Figura 1. Código QR

Fuente: Masahiro Hara creador del codigo quick response (QR), 1994

diciones para su implementación, dada la orientación tecnológica de este centro de la UNAH y los recursos TIC con los que cuenta y que son necesarios para la utilización educativa de dicha tecnología. A esto se suma, el proceso de fortalecimiento de la innovación educativa impulsado en los últimos años en la UNAH a fin de que sus docentes y estudiantes desarrollen proyectos de innovación y además generar un aprendizaje pertinente y de calidad.

\section{La realidad aumentada: con-} cepto y funcionamiento

La realidad aumentada surge en los años sesenta, cuando Sutherland usó un dispositivo de despliegue de imágenes tridimensionales de tipo casco, para visualizar gráficos en tercera dimensión. Sin embargo, el desarrollo de esta tecnología se ha acentuado en los últimos quince años; ha madurado en hardware, software, aplicaciones y contenidos. Actualmente, muchos celulares, consolas de videojuegos, los dispositivos de geolocalización y las tabletas, ya cuentan con los dispositivos para implementar la realidad aumentada (Lara \& Benítez, 2004, p.5).

Esta realidad aumentada es una tecnología que permite al usuario sumergirse en una simulación gráfica 3D generada por computador y navegar e interactuar en ella en tiempo real, desde una perspectiva centrada en el usuario. La realidad virtual es una experiencia sintética mediante la cual se pretende que el usuario sustituya la realidad física por un entorno ficticio generado por computador (Flórez \& Buriticá, n.d., p. 23).

Los dispositivos especializados más usados son los lentes con monitores montados sobre un armazón tipo gafas, con una cámara colocada sobre el soporte entre los lentes. Estos lentes cuentan con controladores que reconocen diferentes herramientas de software, tales como MagicBook y ARToolkit.

Asimismo, algunos dispositivos móviles como los de geolocalización permiten montar aplicaciones de realidad aumentada y cuentan con cámara de video y pantallas rientadas ortogonalmente y ali-

Figura 2. Marca de Aumentaty Author que muestra una Tarjeta Madre. Fuente: Aumentaty Author, Pérez 2014 


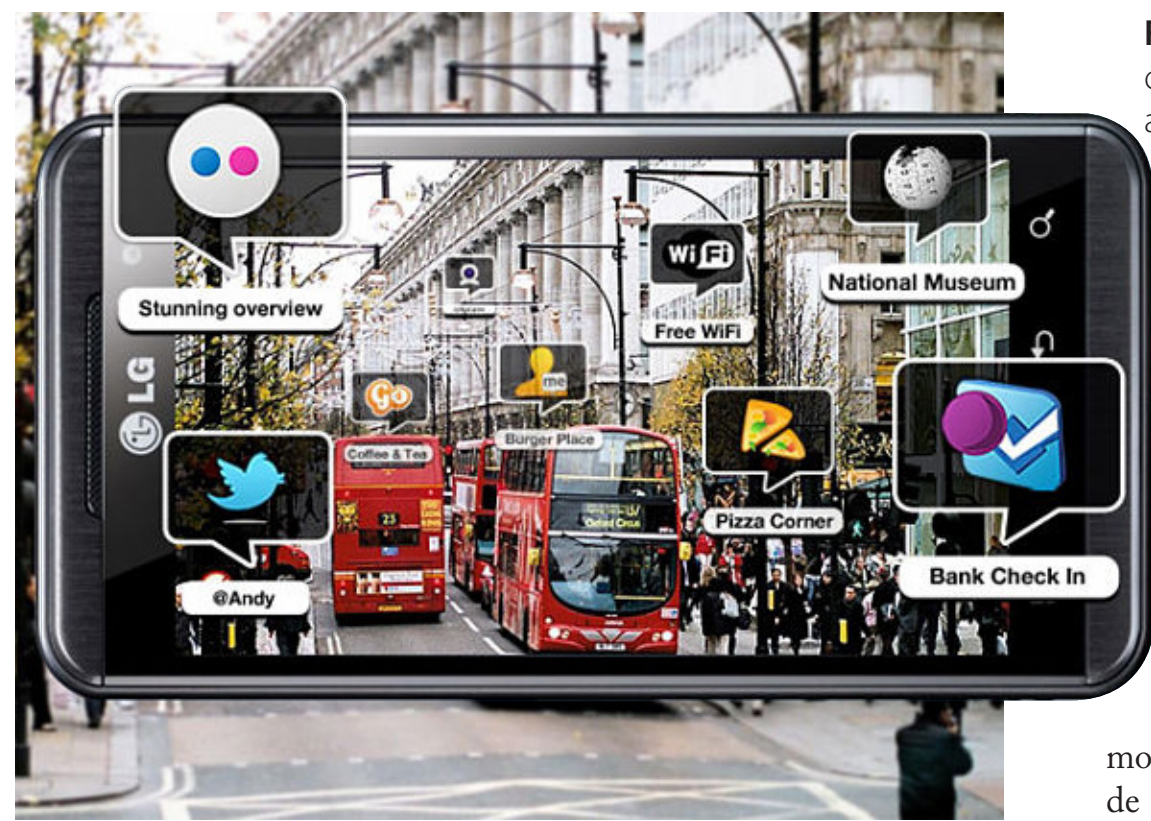

neadas, apuntando uno hacia delante y el otro hacia atrás, lo cual permite configurar una herramienta de realidad aumentada.

Las tabletas también pueden ser configuradas de forma similar; algunas cuentan con cámara y en caso contrario, basta con fijar una webcam en la orientación adecuada (Lara \& Benítez, 2004, p.5).

Según Juniper Research la realidad aumentada en dispositivos móviles generará más de 700 millones de dóleres en el 2014, con más de 350 millones de terminales móviles con capacidad de ejecutar este tipo de aplicaciones (Morcillo, 2011).

¿Cómo funciona la realidad aumentada? La realidad aumentada funciona a través de la integración de objetos y mundos reales y virtuales, a veces agregados, combinados, fusionados o intercambiados, que posibilita la creación y manejo de mundos integrados o realidad mezclada. Esta área de la visualización se basa en una estrategia de visualización e interactividad que hace uso de muchas tecnologías y de diferentes áreas de visualización científica dando lugar a un espectro de modalidades que se mueven alrededor de dos extremos: si el entorno del espacio -el ambiente circundante- es dominantemente virtual y se le agregan objetos virtuales y reales, se habla de realidad virtual; mientras que si el entorno dominante es real y se le agregan objetos virtuales, se habla de realidad aumentada (Lara \& Villarreal, 2004, p. 4).

Esta tecnología que integra señales captadas del mundo real -típicamente video y audio- con señales generadas por computadores -objetos gráficos tridimensionales-. Estas señales se hacen corresponder para construir nuevos mundos coherentes, complementados y enriquecidos. De esa forma se hace coexistir objetos del mundo real y objetos del mundo virtual en el ciberespacio (Lara \& Villarreal, 2004, p. 4).

\section{Tipos de realidad aumentada} Lara \& Villarreal (2004) establecen cuatro categorías de realidad aumentada:

1. El Código QR es un sistema para almacenar información en una matriz de puntos o un código de barras bidimensional, que puede
Figura 3. Superposición de contenidos virtuales a un paisaje urbano. Fuente: Revista de Tecnología, engadget, 2013.

presentarse en forma impresa o en pantalla y son interpretables por cualquier aparato que pueda captar imágenes y cuente con el software adecuado. Este tipo de código puede almacenar hasta 7,089 caracteres y sus posibilidades son muchas, desde codificar información sobre webs, promociones, publicidad, organización de inventarios, entradas y billetes de viajes, mensajes cortos, etc. E1 código $\mathrm{QR}$ es de forma cuadrada y puede ser fácilmente identificado por su patrón de cuadros oscuros y claros en tres de las esquinas del símbolo; su nombre es debido a la frase "Quick Response (Respuesta Rápida)" ya que se diseñó para ser decodificado a gran velocidad. (Huidobro, 2009, págs. 47,48).

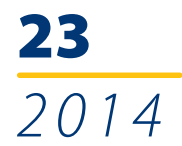

Inicialmente se usó para registrar repuestos en el área de la fabricación de vehículos, hoy, los códigos $\mathrm{QR}$ se usan para administración de inventarios en una gran variedad de industrias. Google ha lanzado anuncios en prensa, McDonalds ofrece información nutricional de sus productos imprimiendo códigos en sus envases, Nike o Coca-Cola realizan campañas en línea basadas en QR. (Huidobro, 2009, págs. $47,48)$.

2. Los marcadores son una especie de plantilla en forma cuadrada que generalmente es de color blanco y negro (colores proporcionalmente distribuidos para facilitar la identificación y transformación del objeto tridimensional) (Leidy Díaz, 2010, pág. 201). En la figura 3 se muestra un marcador o marca generado por 
el software de Aumentaty Author del cual surge un motherboar de $\mathrm{PC}$ en tres dimensiones.

Lo primero que hay que resaltar es la diferencia entre código $\mathrm{QR}$ y marcador. Un marcador sólo es reconocible por el software para el que ha sido diseñado; en cambio un código QR contiene información intrínseca que puede ser leída por cualquier lector de códigos QR. Es decir, un código $\mathrm{QR}$ siempre es un marcador, pero un marcador puede no ser código QR.

3. Superposición de contenidos como texto, imágenes y video a una determinada imagen que en RA se conoce como capas, incluye geolocalización a través de GPS, el que permite al usuario ubicar el dispositivo lector y reconocer su entorno y agregar a él, información disponible en la red; la RA deja ver al usuario el mundo real a su alrededor y aumenta la visión que éste tiene de su entorno mediante la superposición o composición de los objetos $3 \mathrm{D}$ virtuales. Idealmente, esto daría al usuario la ilusión que los objetos de los mundos real y virtual coexisten. (Navarro, 2010, pág. 712)

Este tipo de realidad aumentada está pensada exclusivamente para smartphones, utiliza el hardware de estos dispositivos (GPS, brújula, acelerómetro) para localizar la situación del usuario, y superponer una capa de información sobre los puntos de interés o POI (Point of Interest). Los POI son los elementos virtuales que representan puntos de interés en la RA. Estos puntos aparecerán en la pantalla del dispositivo con la información virtual superpuesta. Los POI pueden ser creados a través de plataformas auxiliares o mediante programación. (Navarro, 2010, pág. 712)

4. Utilización de dispositivos denominados wearables (vestible), como las gafas montadas en la cabeza del usuario que le permite monitorear la realidad agregando a ésta información interactiva en todo momento. Una de las tecnologías más esperadas son los lentes de RA como las Google Glass que son unas gafas de realidad aumen- tada que disponen de una pequeña pantalla lateral donde se muestra información, es decir, es como un smartphone que no necesita que se manipule con las manos, sólo con la voz. (Vidal, 2014, pág. 240)

La realidad aumentada es un recurso tecnológico utilizado por docentes y estudiantes en muchas universidades, a través de textos impresos en los cuales se pueden incluir códigos $\mathrm{QR}$ con enlaces a sitios web para profundizar en determinadas temáticas.

E1 Informe Horizonte 2013 cita ejemplos en el uso de tecnología portátil que utiliza esta realidad aumentada, entre ellos: que a través del uso de lentes los estudiantes de geología puedan saber el estado y materiales del suelo que observan.

\section{Metodología}

Para el desarrollo del diagnóstico se utilizaron fuentes primarias y secundarias. Las fuentes primarias incluyeron a estudiantes y docentes de la Carrera de Informática Administrativa y autoridades acadé-

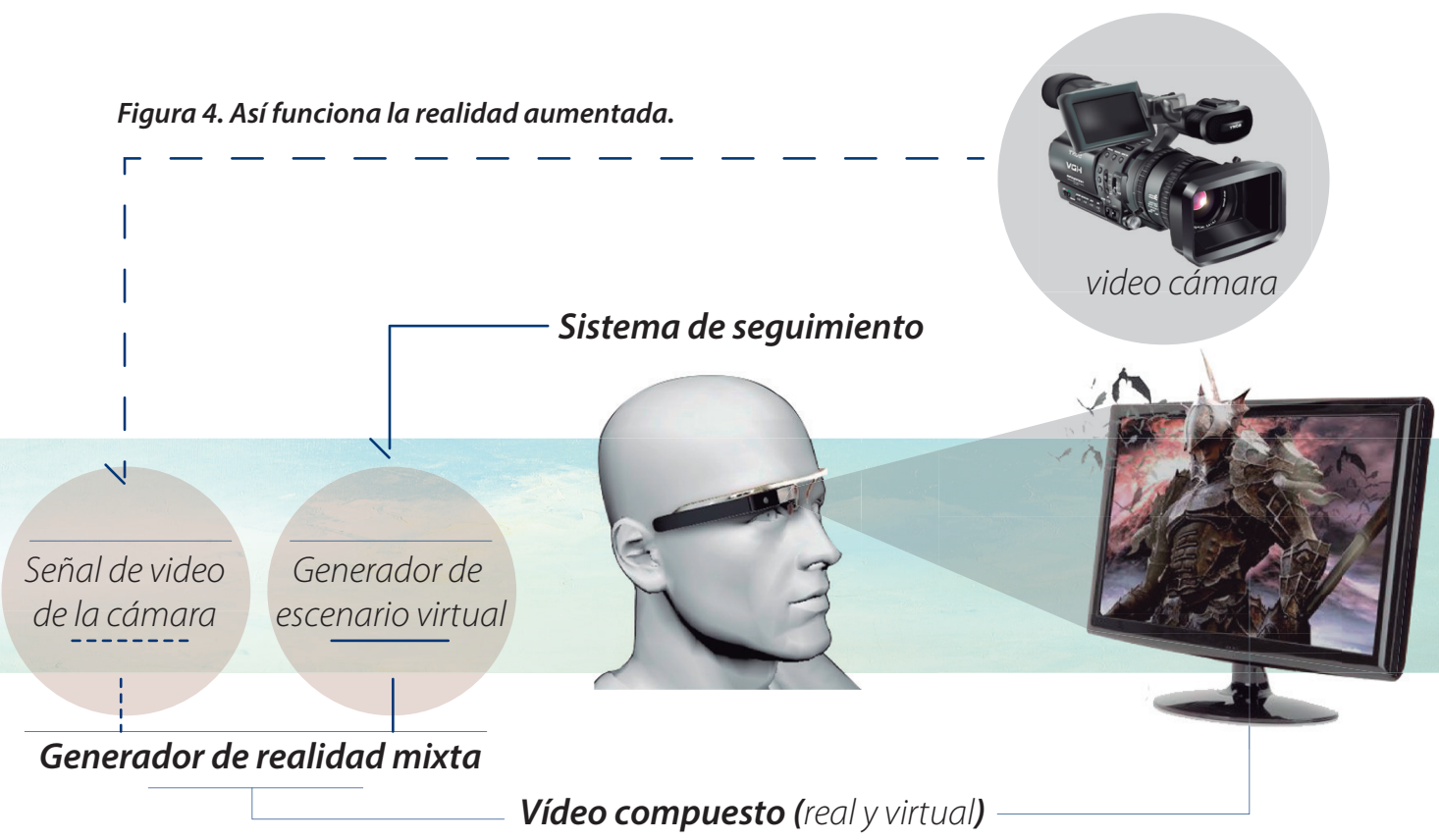

Fuente: Martínez, 2012) 


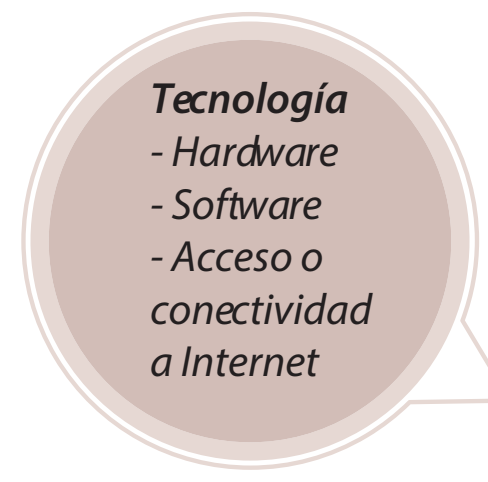

micas de UNAH TEC Danlí. Las técnicas seleccionadas fueron la encuesta y la entrevista. Como fuentes secundarias se consultaron: tesis, revistas y publicaciones científicas obtenidas por medio de Internet.

Se realizó preliminarmente un sondeo con 100 estudiantes de la carrera de Informática Administrativa de UNAH TEC Danlí, matriculados en el I Periodo Académico 2014, quienes fueron escogidos de forma aleatoria. Con este grupo de estudiantes se auscultó el conocimiento sobre el término de realidad aumentada.

Posteriormente se aplicó una encuesta a una muestra de 164 alumnos y seis docentes de la misma carrera y se entrevistó además, a 3 autoridades académicas de UNAH TEC Danlí.

Del total de estudiantes encuestados 90 eran del sexo femenino y 74 del masculino. En el caso de los docentes cinco corresponden al sexo masculino y uno al femenino. Asimismo, el 83\% de los profesores tienen edades arriba de los 30 años, esto los ubica como migrantes digitales en el sentido de que tienen que capacitarse en las tecnologías emergentes, ajenas a la cultura y contexto bajo el que crecieron y se formaron.

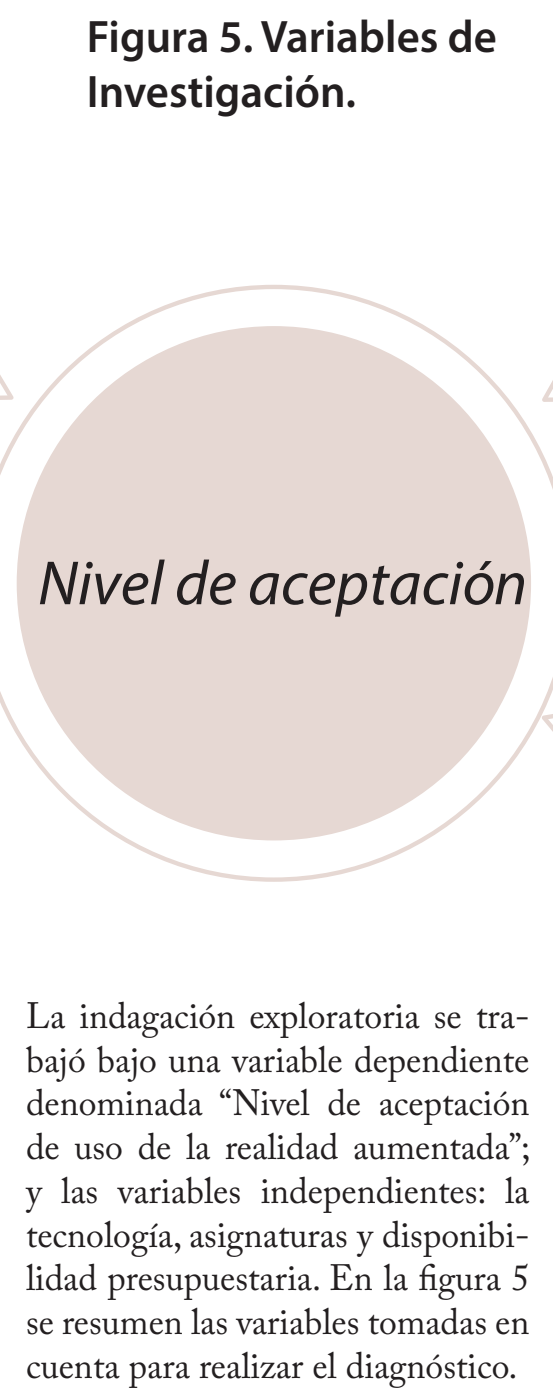

\section{Resultados}

Los resultados observados reflejan datos significativos ya que tanto estudiantes como docentes muestran un conocimiento de las TIC que supera el 60\% de los conocimientos tecnológicos requeridos para el uso de la realidad aumentada. Además muestran interés elevado por el estudio y utilización de este tipo de tecnología.

Es así como en los alumnos, los resultados indican que se encuentran por encima del nivel mínimo de aceptación (60\%) como se observa en la figura 6 Esto permite identifi-

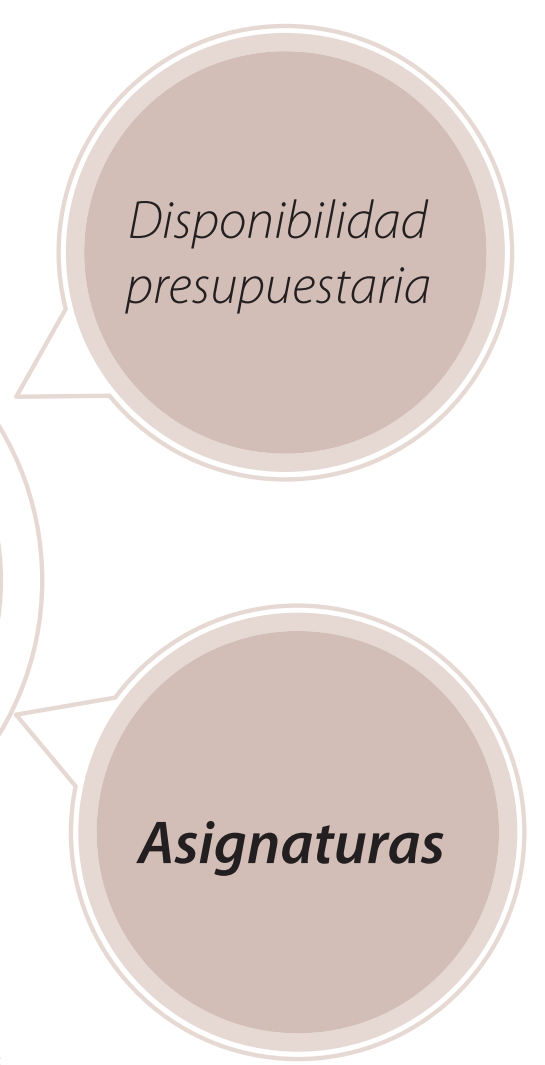

car que existen las condiciones para la implementación de la RA en el proceso enseñanza en la carrera de Informática de UNAH TEC Danlí.

En cuanto al conocimiento de las TIC por parte de los profesores, la tendencia es la misma que la registrada en los estudiantes, como se muestra en el figura 7.

En relación al nivel de aceptación del uso de la realidad aumentada, el porcentaje es significativo, ya que el $88 \%$ de los alumnos consideran importante o muy importante el uso de la realidad aumentada como recurso didáctico en las clases de la carrera de Informática Administrativa, en oposición a un $12 \%$ que lo considera más o menos significativo.

Se nota la brecha generacional entre estudiantes y docentes, ya que 
en este mismo punto solo el $66 \%$ de los maestros consideran importante o muy importante el uso de la realidad aumentada como recurso didáctico en sus clases; mientras que el $34 \%$ considera más o menos útil el usar la RA en las clases que imparten.

En relación a la variable "asignaturas", considerando el número de materias aptas para utilizar la RA como recurso didáctico tomando como base las 20 asignaturas que pertenecen a la carrera de Informática Administrativa, los datos muestran que alumnos y maestros consideran que las clases de Taller de Hardware I y II, Redes de Computadoras, Sistemas Operativos I y II, Comunicación Electrónica de Datos, Perspectiva de la Tecnología Informática y Administración, y Evaluación de Proyectos de Informática, son aptas para el uso de la realidad aumentada como recurso didáctico en apoyo para la mejor comprensión de los contenidos de dichas asignaturas.

En el caso de la variable "tecnología”, se concluye que más del $50 \%$ de los estudiantes y docentes encuestados poseen el equipo tecnológico mínimo para el uso de la realidad aumentada.

Dentro del software evaluado están

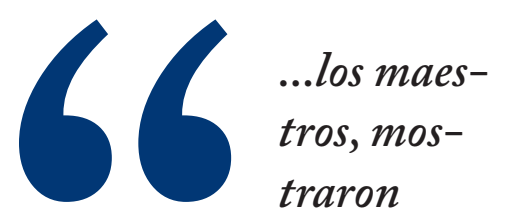

interés en usar la realidad aumentada como recurso

didáctico en las asignaturas de la carrera de Informática Administrativa de UNAH-TEC Danlí..

los sistemas operativos Microsoft, Mac O.S., Linux, Unix y otros. Donde el software predominante en las computadoras personales de los alumnos, es el sistema operativo de la plataforma Microsoft.

En el tema de acceso a conectividad, esencial para el uso de la RA, los resultados muestran que el $39.6 \%$ de los alumnos tienen acceso o conexión a Internet por más de 12 horas diarias, es decir que poseen acceso a Internet fuera de la universidad. Esto facilita que el alumno pueda utilizar la realidad aumentada desde su casa u otros espacios extra universidad, como un recursos para direccionar hacia URL, descargar documentos (doc, xlx, pdf, etc.) o archivos varios (video, audio).
En la variable de "disponibilidad presupuestaria para adquirir la tecnología que posibilite el uso de la RA”, el diagnóstico mostró que existen las condiciones financieras para disponer de estos recursos tecnológicos.

\section{Conclusiones}

Se ha logrado identificar que la mayoría de las asignaturas que cursan los estudiantes encuestados son de naturaleza teórica-práctica, que utilizan metodologías de laboratorio donde se puede añadir contenidos de realidad aumentada para reforzar el aprendizaje de los estudiantes.

Se pudo determinar que en UNAHTEC Danlí tanto estudiantes como docentes cuentan con los requerimientos tecnológicos mínimos, necesarios para la utilización de contenidos de realidad aumentada. Con la evaluación de la disponibilidad presupuestaria, se pudo evaluar que sí existe disponibilidad presupuestaria para adquirir nuevos dispositivos por parte de alumnos y docentes para interactuar con los contenidos de RA propuestos. Además la misma tecnología vendría a reducir los costos del material didáctico utilizado por docentes y alumnos.

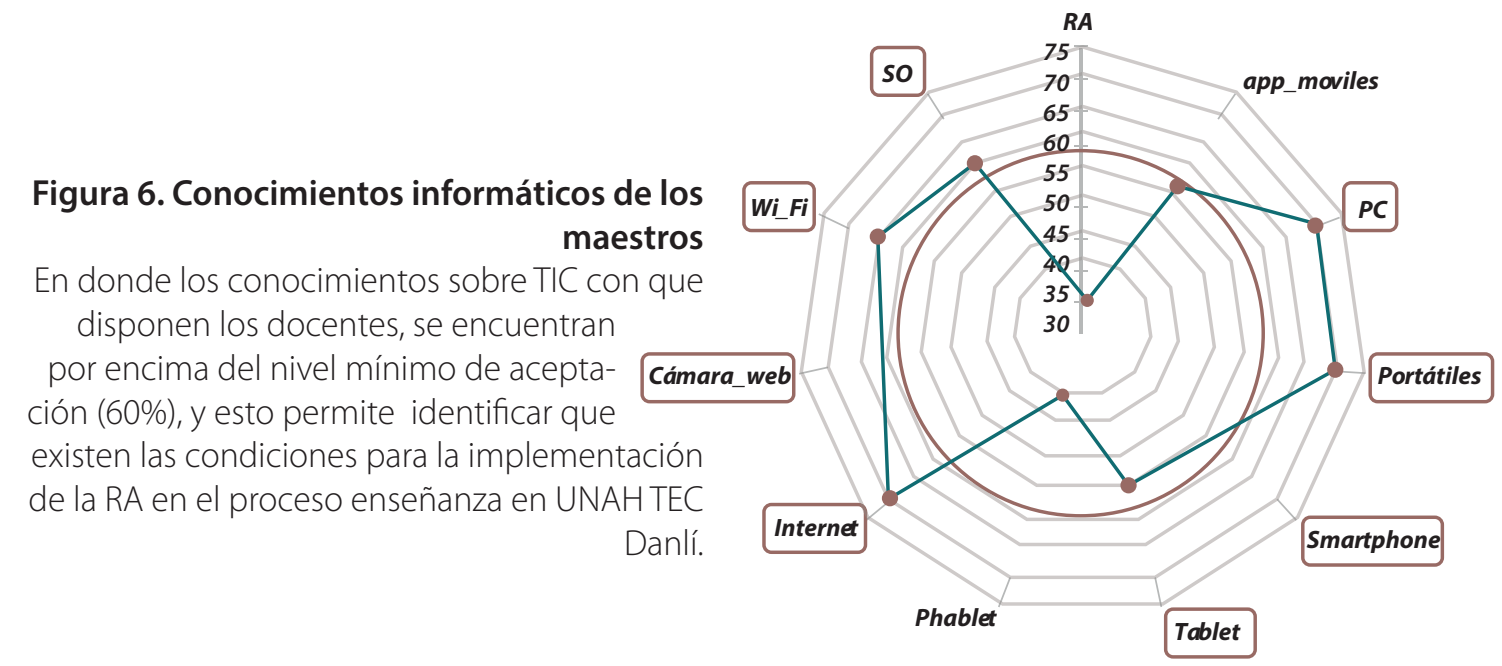

herramient@s 


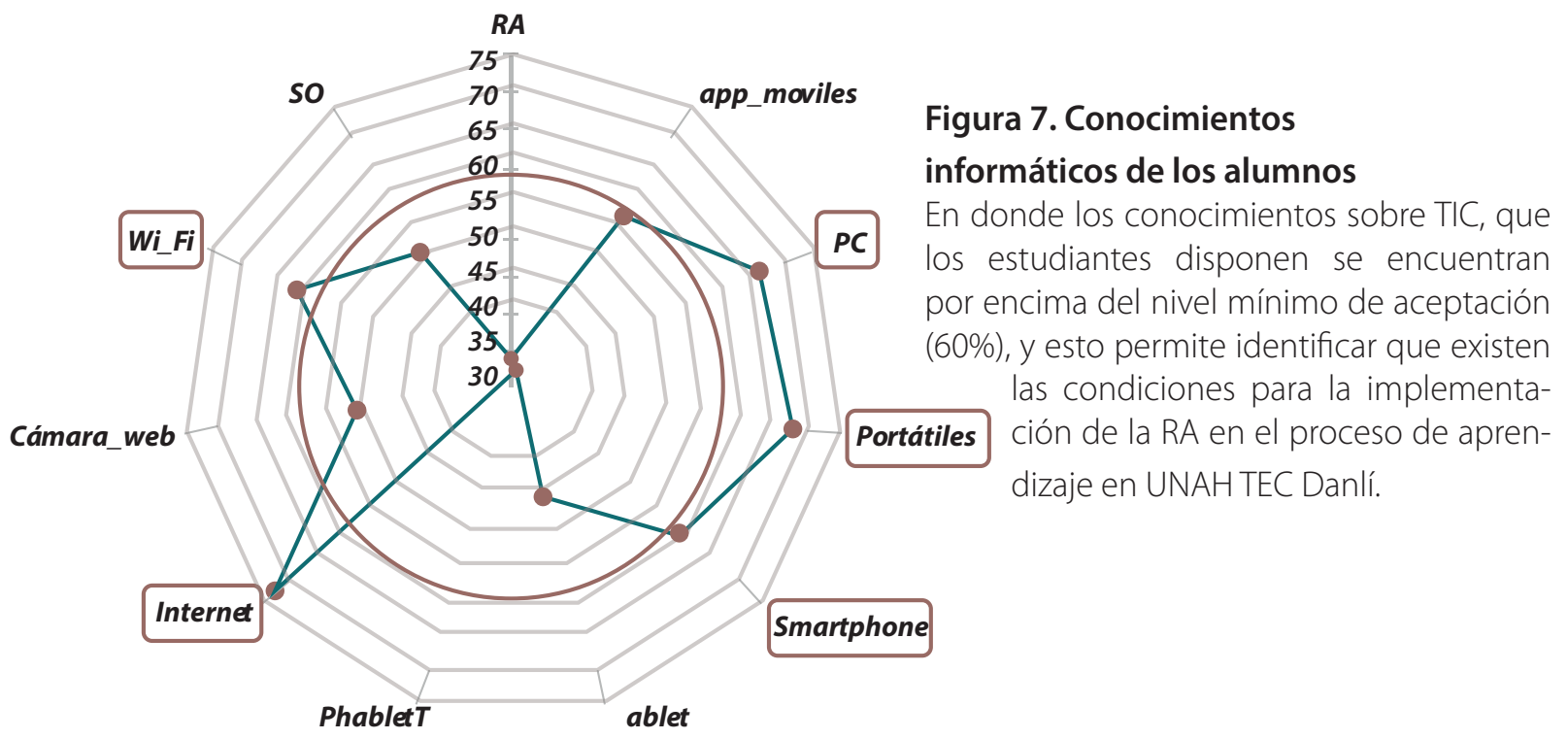

Se puede afirmar que tanto los alumnos como los maestros, mostraron un alto interés en usar la realidad aumentada como recurso didáctico en las asignaturas de la carrera de Informática Administrativa de UNAH-TEC Danlí, para lograr aprendizajes significativos de los alumnos e innovar en la práctica educativa de los profesores.

\section{Referencias}

Flórez, J. C., \& Buriticá, M. F. (n.d.). Realidad Aumentada aplicada a Objetos de Aprendizaje para Asignaturas de Ingeniería Informática. Recuperado de http://www.eduteka.org/gestorp/ $\mathrm{recUp} / 5 \mathrm{fb} 29 \mathrm{c} 87337686 \mathrm{de} 2 \mathrm{bc} 60 \mathrm{f}-$ c7e4037338.pdf

Huidobro, J. M. (2009). Código QR. BIT, 47, 48.

Larva, L. H., \& Benítez, J. V. (2004). La realidad aumentada: una tecnología en espera de usuarios. Revista Digital Universitaria, 5(7). Recuperado de http://www.revista. unam.mx/vol.8/num6/art48/jun_ art48.pdf
Leidy Díaz, S. N. (2010). Realidad Aumentada: Un Sendero por Descubrir. Artículo Monográfico, 201. Lizbeth Heras Lara, J. L. (2004). Realidad Aumentada, Una Tecnología en Espera de Usuarios. Mexico, D.F.

Johnson, L., Adams Becker, S., Cummins, M., Estrada, V., Freeman, A., Ludgate, H. (2013). NMC Horizon Report: Edición sobre Educación Superior 2013. Traducción al español realizada por la Universidad Internacional de La Rioja, España (www.unir.net). Austin, Texas: The New Media Consortium.

Martínez, J. d. (2012). Realidad Aumentada: Una Alternativa Metodológica en la Educación Primaria Nicaragüense. Nicaragua.

Morcillo, F. J. (2011). Realidad Aumentada Un Enfoque Práctico con ARToolkit y Blender. Bubok Publishing.

Rubén Navarro, C. G. (2010). Re- cursos didácticos para la educación a distancia: hacia la contribución de 1a RA. IDE@S CONCYTEG, 712 .

Vidal, C. M. (2014). Desde la empresa. Pasos, 240

Recibido: 14/08/2014 Aceptado: 12/10/2014 